\title{
An Extension of a Fixed Point Result in Cone Banach Space
}

\author{
Elvin $\operatorname{Rada}^{1}$, Agron Tato $^{2}$ \\ ${ }^{1}$ Department of Mathematics, Facultyof Natural Sciences, University of Elbasan, Elbasan, Albania \\ ${ }^{2}$ Department of Mathematics, Polytechnic University of Tirana, Tirana, Albania
}

\section{Email address:}

elvinrada@yahoo.com(E. Rada), agtato@gmail.com (A. Tato)

\section{To cite this article:}

Elvin Rada, Agron Tato. An Extension of a Fixed Point Result in Cone Banach Space. Pure and Applied Mathematics Journal. Vol. 4, No. 3, 2015, pp. 70-74.doi: 10.11648/j.pamj.20150403.12

\begin{abstract}
In this paper we study a class of mappings in a ConeBanach Space which have at least one fixed point. More precisely for a closed and convex subset $\mathrm{C}$ of a cone Banach space with a generalized norm that satisfy a special condition. We are proposing some extensions of the results of Karapinar.
\end{abstract}

Keywords: Fixed Point, Contraction, Cone Banach Space

\section{Introduction and Preliminaries}

In recent times, fixed point theory has been developed considerably in partially ordered metric spaces; that is, metric spaces endowed with a partial ordering. The application of mathematical modelling is highly relevant for different fields of science, such as engineering, physics, economics etc. A central issue in this topic is the rate of convergence of iterative or approximation processes. In this study we indirectly address this problem by extending some convergence theorems.

Rzepecki[1] in 1980 was the first that introduced the concept of a generalized metric $d_{E}$ on a set $X$ in a way that $d_{E}: X \times X \rightarrow S$, where $E$ is Banach space and $S$ is a normal cone in $E$ with partial order $\leq$. In that paper, theauthor generalized the fixed point theorems of Maia type [2].

Seven years later Lin [3] considered the notion of K-metric space by replacing real numbers with cone $\mathrm{K}$ in metric function, that is $d: X \times X \rightarrow K$.

In 2007, Huang and Zhang [4] announced the notion of cone metric spaces (CMS) by replacing real numbers with an ordering Banach space. In that paper, they also discussed some properties of convergence of sequences and proved the fixed point theorems of contractive mapping for cone metric spaces.

Recently, many results on fixed point theorems have been extended to cone metric spaces.( see example [38]).Karapinar [5] proved some fixed point theorems for self mappings satisfying some contractive condition in these spaces. Notice also that in ordered abstract spaces, existence of some fix point theorems is presented and applied the resolution of matrix equations (see e.g. 12)

Throughout this paper $E:=(E,\|\|$.$) stands for real Banach$ space. Let $P:=P_{E}$ always be a closed nonempty subset of $E . P$ is called cone if $a x+b y \in P$ for all $x, y \in P$ and nonnegative numbers $a, b$ where $P \cap(-P)=\{0\}$ and $P \neq\{0\}$

For a given cone $P$, one can define a partial ordering (denoted by $\leq$ or $\leq_{P}$ ) with respectto $P$ by $x \leq y$ if and only if $y-x \in P$. The notation $x<y$ indicates that $x \leq y$ and $x \neq y$ while $x \ll y$ will show $y-x \in \operatorname{int} P$ where int $P$ denotes the interior of $P$. From now on, it isassumed that int $P \neq \phi$

The cone $P$ is called

$(N)$ normal if there is a number $K \geq 1$ such that for all $x, y \in E$ :

$$
x \leq y \Rightarrow\|x\| \leq K\|y\|
$$

(R) Regular if every increasing sequence which is bounded from above is convergent.

That is, if $\left\{x_{n}\right\}_{n \geq 1}$ is a sequence such that $x_{1} \leq x_{2} \leq \cdots \leq y$ for some $y \in E$, then there is $x \in E$ such that $\lim _{n \rightarrow \infty}\left\|x_{n}-x\right\|=0$ 
In $(N)$ the least positive integer $K$, satisfying (1.1), is called the normal constant of $P$.

\section{Lemma 1.1 (see [6, 10])}

(i) Every regular cone is normal.

(ii) For each $k>1$, there is a normal cone with normal constant $K>k$.

(iii) The cone $P$ is regular if every decreasing sequence which is bounded from below isconvergent.

Proofs of (i) and (ii) are given in [6] and the last one follows from definition.

\section{Definition 1.2 (see [4])}

Let $X$ be a nonempty set. Suppose the mapping $d: X \times X \rightarrow E$ satisfies

(M1) $0 \leq d(x, y)$ for all $x, y \in X$,

$(M 2) d(x, y)=0$ if and only if $x=y$

(M3) $d(x, y) \leq d(x, z)+d(z, y)$ for all $x, y \in X$,

(M4) $d(x, y)=d(y, x)$ for all $x, y \in X$,

then $d$ is called cone metric on $X$, and the pair $(X, d)$ is called a cone metric space (CMS).

\section{Example 1.3.}

Let $E=\mathbb{R}^{3}$,

$P=\{(x, y, z) \in E: x, y, z \geq 0\}$, and $X=\mathbb{R}$. Define

$d: X \times X \rightarrow E$

by $d(x, \tilde{\mathbf{x}})=\left(\frac{1}{2}\left|x^{3}-\tilde{x}^{3}\right|, \frac{1}{3}\left|x^{3}-\tilde{x}^{3}\right|, \frac{1}{4}\left|x^{3}-\tilde{x}^{3}\right|\right)$. Then $(X, d)$ is a CMS. Note that the cone $P$ is normal with the normal constant $K=1$.

It is quite natural to consider Cone Normed Spaces (CNS).

\section{Definition 1.4 (see[7], [11])}

Let $X$ be a vector space over $\mathbb{R}$. Suppose the mapping $\|\cdot\|_{p}: X \rightarrow E$ satisfies:

(N1) $\|x\|_{P}>0$ for all $x \in X$

(N2) $\|x\|_{P}=0$ if and only if $x=0$

(N3) $\|x+y\|_{P} \leq\|x\|_{P}+\|y\|_{P} x, y \in X$

(N4) $\|k x\|_{P}=|k| \cdot\|x\|_{P}$ for all $k \in \mathbb{R}$

then $\|.\|_{\mathrm{p}}$ is called cone norm on $X$, and the pair $\left(\mathrm{X},\|.\|_{\mathrm{p}}\right)$ is called a cone normed space (CNS).

Note that each CNS is CMS. Indeed, $d(x, y)=\|x-y\|_{P}$

\section{Definition 1.5.}

Let $(X,\|\|$.$) be a CNS, x \in X$ and $\left\{x_{n}\right\}_{n \geq 1}$ a sequence in $X$. Then

(i) $\left\{x_{n}\right\}_{n \geq 1}$ converges to $x$ whenever for every $c \in E$ with
$0 \ll c$ there is a naturalnumber $N$, such that $\left\|x_{n}-x\right\|_{P} \leq c$ for all $n \geq N$. It is denoted by $\lim _{n \rightarrow \infty} x_{n}=x$ or $x_{n} \rightarrow x$

(ii) $\left\{x_{n}\right\}_{n \geq 1}$ is a Cauchy sequence whenever for every $c \in E$ with $0 \ll c$ there is a natural number $N$, such that $\left\|x_{n}-x\right\|_{P} \ll c$ for all $n, m \geq N$.

(iii) $(X,\|\|$.$) is a complete cone normed space if every$ Cauchy sequence is convergent.

Complete cone normed spaces will be called cone Banach spaces.

\section{Lemma 1.6.}

Let $(X,\|\|$.$) be a CNS, \mathrm{P}$ a normal cone with normal constant $\mathrm{K}$, and $\left\{x_{n}\right\}$ a sequence in $\mathrm{X}$. Then,

(i)the sequence $\left\{x_{n}\right\}$ converges to $x$ if and only if $\left\|x_{n}-x\right\|_{P} \rightarrow 0$, as $n \rightarrow \infty$;

(ii)the sequence $\left\{x_{n}\right\}$ is Cauchy if and only if $\left\|x_{n}-x_{m}\right\|_{P} \rightarrow 0$ as $n, m \rightarrow \infty$

(iii)the sequence $\left\{x_{n}\right\}$ converges to $x$ and the sequence $\left\{y_{n}\right\}$ converges to $y$ then $\left\|x_{n}-y_{n}\right\|_{P} \rightarrow\|x-y\|_{P}$

The proof is direct by applying [4] to the cone metric space $(X, d)$

where $d(x, y) \rightarrow\|x-y\|_{P}$, for all $x, y \in X$.

\section{Lemma 1.7 [7].}

Let $\left(\mathrm{X},\|\cdot\|_{\mathrm{p}}\right)$ be a CNS over a cone $\mathrm{P}$ in $\mathrm{E}$. Then:

(i) $\operatorname{int}(P)+\operatorname{int}(P) \subseteq \operatorname{int}(P)$ and $\lambda \operatorname{int}(P) \subseteq \operatorname{int}(P), \lambda>0$.

(ii)If $c \gg 0$ then there exists $\delta>0$ such that $\|b\|<\delta$ implies $b \ll c$

(ii)For any given $c \gg 0$ and $c_{0} \gg 0$, there exists $n_{0} \in N$ such that $c_{0} / n_{0} \ll c$.

(iv)If $a_{n}, b_{n}$ are sequences in $E$ such that $a_{n} \rightarrow a, b_{n} \rightarrow b$, and $a_{n} \leq b_{n}$, for all $n$ then $a \leq b$.

The proofs of the first two parts followed from the definition of $\operatorname{int}(P)$. The third partis obtained by the second part. Namely, if $c \gg 0$ is given then find $\delta>0$ such that $\|b\|<\delta$, implies $b \ll c$. Then find $n_{0}$ such that $1 / n_{0}<\delta /\left\|c_{0}\right\|$ and hence $c_{0} / n_{0} \ll c$ Since $P$ is closed, the proof of fourth part is achieved.

\section{Main Results}

\section{Theorem 2.1.}

Let $\mathrm{C}$ be a closed and convex subset of a cone Banach space $\mathrm{X}$ with norm $\|x\|_{P}=d(x, 0)$ and $T: C \rightarrow C a$ a mapping which satisfies the condition 


$$
d(x, T x)+d(y, T y) \leq p \cdot d(x, y)(2.1)
$$

for all $x, y \in C$ and $\lambda>1$, where $\lambda \leq p \leq 2 \lambda$, Then $T$ has at least one fixed point.

Proof. Let $x_{0} \in C$ be an arbitrary point, Define a sequence $\left\{x_{n}\right\}$ as follows:

$$
x_{n+1}:=\frac{(\lambda-1) x_{n}+T\left(x_{n}\right)}{\lambda} n=0,1,2, \ldots
$$

Notice that

$$
x_{n}-T x_{n}=\lambda\left(x_{n}-\left(\frac{(\lambda-1) x_{n}+T x_{n}}{\lambda}\right)=\lambda\left(x_{n}-x_{n+1}\right)\right.
$$

which can write

$$
d\left(x_{n}, T x_{n}\right)=\left\|x_{n}-T x_{n}\right\|=\lambda\left\|x_{n}-x_{n+1}\right\|=\lambda d\left(x_{n}, x_{n+1}\right)(2.4)
$$

for $n=0,12, \ldots$ If we substitute $x=x_{n-1}$ and $y=x_{n}$ ? then from (2.1) and (2.4) we obtain

$$
\lambda d\left(x_{n-1}, x_{n}\right)+\lambda d\left(x_{n}, x_{n+1}\right) \leq p d\left(x_{n-1}, x_{n}\right)(2.5)
$$

Thus, $d\left(x_{n}, x_{n+1}\right) \leq \frac{p-\lambda}{\lambda} d\left(x_{n-1}, x_{n}\right)$ where $0<\frac{p-\lambda}{\lambda}<1$ or $1<\lambda<p<2 \lambda$. Hence, the sequence $\left\{x_{n}\right\}$ is a Cauchy sequence in $\mathrm{C}$ then it converges to the point $z \in C$. Regarding the inequality $d\left(z, T x_{n}\right) \leq d\left(z, x_{n}\right)+d\left(x_{n}, T x_{n}\right)=d\left(z, x_{n}\right)+\lambda d\left(x_{n}, x_{n+1}\right) \quad$ and the Lemma (1.6) we have

$$
T x_{n} \rightarrow z
$$

If we substitute $x=z$ and $y=x_{n}$ ? then inequation(2.1) and (2.3) imply

$$
d(z, T z)+\lambda d\left(x_{n}, x_{n+1}\right) \leq p d\left(z, x_{n}\right)
$$

When $n \rightarrow \infty$, one can get $d(z, T z) \leq 0$, that is $T z=z$.

If the coefficient $\lambda$ take the value $\lambda=2$, one obtains the follow theorem

\section{Theorem 2.2. (Karapinar (2009))}

Let $C$ be a closed and convex subset of a cone Banach space $\mathrm{X}$ with norm $\|x\|_{P}=d(x, 0)$ and $T: C \rightarrow C$ a mapping which satisfies the condition

$$
d(x, T x)+d(y, T y) \leq p d(x, y)
$$

for all $x, y \in C$ and $\lambda>1$, where $1 \leq p \leq 2$. Then, $\mathrm{T}$ has at least one fixed point.

\section{Theorem 2.3.}

Let $C$ be a closed and convex subset of a cone Banach space $\mathrm{X}$ with norm $\|x\|_{P}=d(x, 0)$ and $T: C \rightarrow C$ a mapping which satisfies the condition.

$$
(T x, T y)+d(x, T x)+d(y, T y) \leq q d(x, y)(2.6)
$$

for all $x, y \in C$ and $\lambda>1$, where $\lambda \leq q \leq 2 \lambda+1$. Then, $T$ has at least one fixed point.

Proof. Construct the sequence $\left\{x_{n}\right\}$ in same way as in proof of the theorem (2.1)and equalities (2.2) and (2.3) hold. Let we see also

$$
x_{n}-T x_{n-1}=\frac{(\lambda-1) x_{n-1}+T x_{n-1}}{\lambda}-T x_{n-1}=\frac{\lambda-1}{\lambda}\left(x_{n-1}-T x_{n-1}\right)
$$

from that

$$
d\left(x_{n}, x_{n-1}\right)=\left\|x_{n}-T x_{n-1}\right\|_{p}=\frac{\lambda-1}{\lambda}\left\|x_{n-1}-T x_{n-1}\right\|_{p}=\frac{\lambda-1}{\lambda} d\left(x_{n-1}, T x_{n-1}\right)(2.8)
$$

Triangle inequality for the points $x_{n}, T x_{n}$ and $T x_{n-1}$ implies

$$
d\left(x_{n}, T x_{n}\right)-d\left(x_{n}, T x_{n-1}\right) \leq d\left(T x_{n-1}, T x_{n}\right)
$$

then by (2.4), (2.7) and (2.8) we obtain

$$
\lambda d\left(x_{n}, x_{n+1}\right)-\frac{\lambda-1}{\lambda} d\left(x_{n-1}, T x_{n-1}\right) \leq d\left(T x_{n-1}, T x_{n}\right)(2.1
$$

Replacing $x=x_{n-1}$ and $y=x_{n}$ in (2.6) we have

$$
d\left(T x_{n-1}, T x_{n}\right)+d\left(x_{n-1}, T x_{n-1}\right)+d\left(x_{n}, T x_{n}\right) \leq q \cdot d\left(x_{n-1}, x_{n}\right)(2.1
$$

regarding (2.9), (2.10) and (2.8) one can obtain

$$
\begin{aligned}
& \lambda d\left(x_{n}, x_{n+1}\right)-\frac{\lambda-1}{\lambda} d\left(x_{n-1}, T x_{n-1}\right)+ \\
& +\mathrm{d}\left(\mathrm{x}_{n-1}, T x_{n-1}\right)+d\left(x_{n}, T x_{n}\right) \leq q d\left(x_{n-1}, x_{n}\right)
\end{aligned}
$$

by ( 2.8$)$

$$
d\left(x_{n}, x_{n+1}\right) \leq \frac{q-1}{2 \lambda} d\left(x_{n-1}, x_{n}\right)
$$

then $0<\frac{q-1}{2 \lambda}<1$ or $1<q<2 \lambda+1$. For these values, the sequence $\left\{x_{n}\right\}$ is a Cauchy sequence that converges to any $z \in C$. Since the sequence $\left\{T x_{n}\right\}$ also converges to $z$ as in proof of the theorem (2.1)under the assumption that $x=z$ and $y=x_{n}$. By means of lemma (1.6) we deduce $d(T z, z)+d(z, T z) \leq 0$ which is equivalent with $z=T z$.

\section{Corrollary 2.4.[5]}

Let $C$ be a closed and convex subset of a cone Banach space $X$ with norm $\|x\|_{P}=d(x, 0)$ and $T: C \rightarrow C$ a mapping which satisfies the condition

$d(T x, T y)+d(x, T x)+d(y, T y) \leq q d(x, y)$ 
for all $x, y \in C$ and $\lambda>1$, where $1 \leq q \leq 5$ Then, $T$ has at least one fixed point.

\section{Theorem 2.5.}

Let $C$ be a closed and convex subset of a cone Banach space $X$ with norm $\|x\|_{P}=d(x, 0)$ and $T: C \rightarrow C$ a mapping which satisfies the condition

$$
d(T x, T y) \leq c d(x, y)
$$

where $0<c<1$. Then $T$ has one fixed point.

Proof.Let we regard again three points $x_{n}, T x_{n}, T x_{n-1}$. The triangle property one can write $d\left(T x_{n}, T x_{n-1}\right) \geq d\left(T x_{n}, x_{n}\right)-d\left(x_{n}, T x_{n-1}\right)$

replacing two terms of the right side with (2.3) and (2.7) we have $d\left(T x_{n}, T x_{n-1}\right) \geq \lambda d\left(x_{n}, x_{n+1}\right)-(\lambda-1) d\left(x_{n-1}, x_{n}\right)$ If we substitute the right side to theinequation (2.13) on can obtain

$$
d\left(x_{n}, x_{n+1}\right) \leq \frac{c+(\lambda-1)}{\lambda} d\left(x_{n}, x_{n-1}\right)
$$

The sequence $\left\{x_{n}\right\}$ is a Cauchy sequence and also convergent if is satisfied the condition $\frac{c+(\lambda-1)}{\lambda}<1$ or $c<1$.

Notice that we get another proof for well knownBanach Theorem in cone Banach space.

\section{Theorem 2.6.}

Let $C$ be a closed and convex subset of a cone Banach space $X$ with norm $\|x\|_{P}=d(x, 0)$ and $T: C \rightarrow C$ a mapping which satisfies the condition

$$
a d(T x, T y)+b(d(x, T x)+d(y, T y)) \leq r d(x, y)
$$

for all $x, y \in C, a, b>1, \lambda>1$, where

$0 \leq r-\lambda b+(\lambda-1) a \leq \lambda(a+b)$. Then, $T$ has at least one fixed point.

Proof.Considering that the sequence $\left\{x_{n}\right\}$ is the same as one as is constructed in previoustheorems. Replace in inequality $x=x_{n-1}$ and $y=x_{n}$ one can obtain

$$
\begin{aligned}
& a\left(T x_{n-1}, T x_{n}\right)+b\left(d\left(x_{n-1}, T x_{n-1}\right)+\right. \\
& +d\left(x_{n}, T x_{n}\right) \leq r d\left(x_{n-1}, x_{n}\right)
\end{aligned}
$$

regarding inequalities (2.3) and (2.7) we have

$$
\begin{aligned}
& (a+b)\left(x_{n}, T x_{n}\right)+b\left(d\left(x_{n-1}, T x_{n-1}\right)-d\left(x_{n}, T x_{n-1}\right) \leq\right. \\
& \leq r d\left(x_{n-1}, x_{n}\right)
\end{aligned}
$$

or

$$
\begin{aligned}
& (a+b) \lambda d\left(x_{n}, x_{n+1}\right)+(b \lambda-\lambda+1) \mathrm{d}\left(\mathrm{x}_{n-1}, x_{n}\right) \leq \\
& \leq \operatorname{rd}\left(x_{n-1}, x_{n}\right)
\end{aligned}
$$

The inequality $d\left(x_{n}, x_{n+1}\right) \leq \frac{r-b \lambda+(\lambda-1) a}{\lambda(a+b)} d\left(x_{n-1}, x_{n}\right)$.

implies that if $0<\frac{r-b \lambda+(\lambda-1) a}{\lambda(a+b)}<1$ above sequence is a

Cauchy sequence. Further, proof is same as above theorems.

\section{Corrollary 2.7.[5]}

Let $C$ be a closed and convex subset of a cone Banach space $X$ with norm $\|x\|_{P}=d(x, 0)$ and $T: C \rightarrow C$ a mapping which satisfies the condition

$0 \leq r+|a|-2 b<2(a+b)$

$a d(T x, T y)+b(d(x, T x)+d(y, T y)) \leq r d(x, y), \quad$ for $\quad$ all

$x, y \in C$. Then, $T$ has at least one fixed point.

This proposition derives from above theorem for $\lambda=2$.

\section{References}

[1] Rzepecki, B., "On fixed point theorems of Maia type," Publications de l'InstitutMath'ematique, vol. 28_42_, pp. 179-186, 1980.

[2] Maia, M.G., “Un'osservazionesullecontrazionimetriche," RendicontidelSeminarioMatematicodellaUniversit'a di Padova, vol. 40, pp. 139-143, 1968.

[3] Lin, S. D., "A common fixed point theorem in abstract space" Indian Journal of Pure and Applied Mathematics. Vol. 18, no.8, pp. 685-690.1987

[4] Huang L,-G., Zhang, X., "Cone metric spaces and fixed point theorems of contractive mappings,'Journal of Mathematical Analysis and Applications, vol. 332, no. 2, pp. 1468-1476, 2007

[5] Karapinar, E., Fixed point theorems in Cone Banach Spaces. Hindawi Publishing Company. Vol. 2009.Article ID 609281, 9 pages.

[6] Rezapour Sh., and Hamlbarani, R., "Some notes on the paper: "Cone metric spaces and fixed point theorems of contractive mappings"," Journal of Mathematical Analysis and Applications, vol. 345, no. 2, pp. 719-724, 2008.

[7] Turkoglu, D., Abuloha, M., and Abdeljawad, T., "KKM mappings in cone metric spaces and some fixed point theorems," Nonlinear Analysis: Theory, Methods \& Applications, vol. 72, no. 1, pp. 348-353, 2010.

[8] [8]Sahin I., Telci, M., "Fixed points of contractive mappings on complete cone metric spaces," Hacettepe Journal of Mathematics and Statistics, vol. 38, no. 1, pp. 59-67, 2009.

[9] Suzuki, T., "Fixed point theorems and convergence theorems for some generalized nonexpansive mappings," Journal of Mathematical Analysis and Applications, vol. 340, no. 2, pp. 1088-1095, 2008. Fixed Point Theory and Applications 9.

[10] Deimling, K., Nonlinear Functional Analysis, Springer, Berlin, Germany, 1985.

[11] Abdeljawad T., Karapinar, E., "Quasicone Metric Spaces and Generalizations of Caristi Kirk's Theorem," Fixed Point Theory and Applications, vol. 2009, p. 9 page, 2009. 
[12] Nieto, J. J., Rodrigez-Lopez, R., "Existence and uniqueness of fixed point in partially ordered sets and applications to ordinary differential equations" ActaMathematicaSinica, vol.23, no.12, pp.2205-2212, 2007. 